Revista Eletrônica de Farmácia

Eletronic Journal of Pharmacy

ISSN 1808-0804

doi 10.5216/ref.v16ie.49497

Artigo Original

\title{
Estudo do efeito central do óleo do fruto de Attalea phalerata Mart. ex Spreng. em modelos animais de ansiedade e depressão
}

\section{Study of central effects of Attalea phalerata Mart. ex Spreng. fruit oil in animal models of anxiety and depression}

\section{Estudio del efecto central del aceite del fruto de Attalea phalerata Mart. ex Spreng. en modelos animales de ansiedad y depresión}

\author{
LIMA, Fernando Freitas de ${ }^{1 *}$. JÚNIOR, Paulo Sérgio Vieira Souza ${ }^{1}$. TRAESEL, Giseli Karenina ${ }^{1}$. TOLOUEI, Sara \\ Emilia Lima ${ }^{2}$. OESTERREICH, Silvia Aparecida ${ }^{1}$. VIEIRA, Maria Carmo ${ }^{3}$. \\ ${ }^{1}$ Faculdade de Ciências da Saúde, Universidade Federal da Grande Douradosourados - FCS/UFGD. ${ }^{2}$ Faculdade de Ciências \\ Biológicas e Ambientais, Universidade Federal da Grande Dourados - FCBA/UFGD. ${ }^{3}$ Faculdade de Ciências Agrárias, Universidade \\ Federal da Grande Dourados - FCA/UFGD. \\ *flfernando_@hotmail.com
}

Resumo. Introdução: Os frutos de Attalea phalerata Mart. ex Spreng. (Arecaceae), conhecidos como bacuri, apresentam elevado valor nutricional devido as grandes quantidades de minerais e lipídios em sua composição. O óleo do fruto é utilizado na medicina popular em forma oral para o tratamento de congestão pulmonar e como anti-inflamatório para doenças articulares. Apresenta em sua composição ácidos graxos insaturados e carotenoides. Estudos indicam que esses compostos exercem importante função no sistema imunológico, bem como na prevenção e tratamento de doenças crônicas. Objetivo: Este estudo teve como objetivo descrever o efeito central do óleo da polpa de frutos de $A$. phalerata (OPAP) em modelos experimentais de ansiedade e depressão. Metodologia: Para avaliação foram empregados os testes de Labirinto em Cruz Elevado, Campo Aberto, Esconder Esferas e Nado Forçado. Resultados e Discussão: Os resultados encontrados a partir dos modelos animais de ansiedade e depressão mostraram que o óleo apresentou efeito ansiolítico com ausência de sedação no teste de Labirinto em Cruz Elevado e Esconder Esferas. Entretanto, nos experimentos de Campo Aberto e Nado Forçado, os animais não apresentaram alterações comportamentais. Conclusão: A análise dos testes comportamentais revelou efeito ansiolítico, sugerindo que o óleo do fruto de Attalea phalerata Mart. ex Spreng. pode exercer efeito sobre o sistema nervoso central. Palavras-chave: Bacuri. Alimentos funcionais. Fitoterápico. Comportamento.

\begin{abstract}
Introduction: The fruits of Attalea phalerata Mart. ex Spreng. (Arecaceae), known as bacuri, present high nutritional value due to the presence of large amounts of minerals and lipids in their composition. The fruit oil is used in popular medicine in oral form to treat pulmonary congestion and as an anti-inflammatory for joints. It has in its composition unsaturated fatty acids and carotenoids. Studies indicate that these compounds have important immune system function, as well as in prevention and treatment of chronic diseases. Objective: This study aimed to describe the potential central effects of the of A. phalerata (OPAP) oil pulp in experimental models of anxiety and depression. Methodology: Tests of elevated Plus-Maze, Open Field, Marble-Burying and Forced Swim were used. Results and discussion: The oil had an anxiolytic effect with absence of sedation in the Elevated Plus-Maze and Marble-Burying tests. However, results of open field and forced swim experiments showed no behavioral changes. Conclusion: The behavioral analysis revealed an anxiolytic effect, suggesting that the fruits oil of Attalea phalerata Mart. ex Spreng. may be involved with these actions in the central nervous system.
\end{abstract}

Key-words: Bacuri. Functional foods. Phytotherapic. Behavior.

Resumen. Introducción: Los frutos de Attalea phalerata Mart. ex Spreng. (Arecaceae), conocidos como bacuri, presentan un alto valor nutricional debido a que presentan grandes cantidades de minerales y lípidos en su composición. El aceite del fruto se utiliza en la medicina popular en forma oral para el tratamiento de congestión pulmonar y antiinflamatorio para las articulaciones. Presenta en su composición ácidos grasos insaturados y carotenoides. Los estudios indican que estos compuestos ejercen una importante función en el sistema inmunológico, así como en la prevención y tratamiento de enfermedades crónicas. Objetivo: Este estudio tuvo como objetivo describir el efecto central del aceite de la pulpa de frutos de A. phalerata (OPAP) en modelos experimentales de ansiedad y depresión. Metodología: Para la evaluación se emplearon las pruebas de Laberinto en Cruz Elevado, Campo Abierto, Esconder Esferas y Nado Forzado. Resultados y Discusión: Después de la evaluación de los parámetros y comportamiento de los animales, el aceite presentó efecto ansiolítico con ausencia de sedación en la prueba de Laberinto en Cruz Elevado y Esconder Esferas. En los experimentos de Campo Abierto y Nado Forzado, los animales no presentaron alteraciones conductuales. Conclusión: El análisis de las pruebas comportamentales reveló efecto ansiolítico sugiriendo que el aceite del fruto de Attalea phalerata Mart. ex Spreng. puede ejercer un efecto sobre el sistema nervioso central.

Palabras-clave: Bacuri. Alimentos funcionales. Fitoterápico. Comportamiento. 


\section{Introdução}

A utilização de espécies vegetais com fins terapêuticos, para tratamento, cura e prevenção de doenças é uma das mais antigas formas de prática medicinal da humanidade. $\mathrm{O}$ desenvolvimento de fármacos de origem vegetal envolve levantamento etnofarmacológico, estudos fitoquímicos e farmacológicos. Os indícios relevantes para a seleção de uma planta para um estudo farmacológico incluem o uso tradicional, a composição química, a toxicidade, a seleção aleatória ou uma combinação de vários critérios $(1,2)$. A seleção de plantas medicinais com vistas à descoberta de novos agentes farmacêuticos com base na sua utilização popular é de longe a estratégia mais eficaz(3).

Após o levantamento etnofarmacológico e estudos fitoquímicos, investigações biológicas são imprescindíveis. Modelos animais de ansiedade e depressão têm desempenhado papéis relevantes no processo de pesquisa de novos fármacos(4). Para o desenvolvimento de novos tratamentos mais eficazes para os distúrbios do humor são necessárias pesquisas que abordem o histórico dessas patologias, tratamentos farmacológicos, investigação de plantas medicinais com propriedades ansiolíticas e antidepressivas, bem como estratégias pré-clínicas para a investigação de extratos ou fitoconstituintes com essas atividades e suas possíveis toxicidades $(5)$.

O valor terapêutico das plantas medicinais decorre do percentual de prescrições médicas com base na fitoterapia, das quais $25 \%$ são derivadas de alguma espécie específica(6). Em todo o mundo, a medicina tradicional representa a principal forma de cuidados de saúde ou complemento a ela(7). Em alguns países, esse tipo de terapia pode ser denominado de medicina complementar e alternativa, sendo uma parte importante de suporte ao tratamento das patologias e, muitas vezes, subestimada nos serviços de saúde(8). A medicina tradicional é a soma total de conhecimentos, habilidades e práticas culturais baseadas em teorias, crenças e experiências indígenas, explicáveis ou não ao diagnóstico e ao tratamento das doenças físicas e mentais(9).

Atualmente, há uma dependência muito acentuada das bases farmacológicas para terapêutica de distúrbios mentais, ou seja, uma necessidade da utilização de drogas sintéticas para curar ou aliviar certos transtornos emocionais. Enquanto isso, pesquisas têm demonstrado que muitas pessoas procuram produtos naturais à base de plantas para o tratamento de diferentes tipos de transtornos psiquiátricos. Nos últimos tempos, as pesquisas estão sendo focadas na validação de plantas medicinais popularmente conhecidas por suas propriedades psicoativas. Assim sendo, compostos importantes que agem sobre o SNC foram isolados de diferentes espécies de plantas e, alguns deles, atualmente vem sendo utilizados na clínica (na sua forma natural ou modificada) para vários distúrbios psiquiátricos(5). Porém, os órgãos reguladores definem medicamentos fitoterápicos como aqueles obtidos com uso exclusivo de plantas com eficácia reconhecida, nível aceitável de segurança, dados científicos, estudos pré-clínicos (farmacológicos e toxicológicos) e publicações clínicas $(10,11)$.

O óleo da polpa de Attalea phalerata Mart. ex Spreng. (Arecaceae) vem sendo utilizado no tratamento de congestão pulmonar e dores nas articulações $(12,13)$. Estudos recentes relatam que o uso do óleo apresenta baixa toxicidade e genotoxicidade, além de ser um promissor agente anti-inflamatório(14-17). As atividades farmacológicas do óleo são atribuídas a presença de compostos bioativos que apresentam atividades benéficas, como os carotenoides e ácidos graxos insaturados $(4,6)$.

Este estudo objetivou avaliar o efeito ansiolítico e antidepressivo do óleo da polpa de frutos de A. phalerata (OPAP) em ratos por meio de experimentos de avaliação neurocomportamental.

\section{Material e Métodos}

\section{Coleta do Material}

Frutos de A. phalerata foram coletados próximo ao município de Rio Brilhante - Mato Grosso do Sul (21 ${ }^{\circ} 48^{\prime} 07^{\prime \prime S}$ 5432'47"W) e levados ao Laboratório do Grupo de Estudos em Produtos e Processos Agroindustriais do Cerrado (LabGEPPAC). Os frutos foram separados a fim de obter um lote uniforme e no mesmo estágio de maturação, sendo posteriormente lavados e higienizados. Para as análises foi realizado o despolpamento dos frutos e secagem da polpa em estufa de circulação de ar em fluxo contínuo a $45^{\circ} \mathrm{C}$. Após $48 \mathrm{~h}$, a polpa desidratada foi triturada e peneirada para obtenção de um pó com granulometria uniforme.

Extração do Óleo

A extração foi realizada com solvente hexano P. A. em razão de uma parte de polpa desidratada em pó para três partes de solvente $1: 3(\mathrm{p} / \mathrm{v})$ sob extração contínua a $45^{\circ} \mathrm{C}$ em ambiente escuro. Após a extração exaustiva, para completa remoção do resíduo sólido, o material foi filtrado e o solvente foi completamente removido sob pressão reduzida a $45^{\circ} \mathrm{C}$ em evaporador rotativo. O óleo da polpa de $A$. phalerata foi então acondicionado em frasco âmbar e refrigerado em temperatura de $10^{\circ} \mathrm{C}$ até o início das análises. $\mathrm{O}$ óleo apresenta cor amarelo-laranja com densidade de 0,921 $\mathrm{g} / \mathrm{L}$, de modo a ser considerado um óleo origem vegetal.

\section{Animais}

As análises in vivo foram realizadas com 25 ratos Wistar machos, 8-10 semanas e peso de 413-434g. Os animais foram divididos em cinco grupos $(n=5)$, sendo que o Grupo I (controle negativo) recebeu solução salina + Tween 80® e os Grupos II, III, IV e V receberam 125, 250, 500 e 1000 mg/kg do OPAP, respectivamente. Durante 7 dias os animais receberam via gavagem os tratamentos no período vespertino. No $7^{\circ}$ dia, no período noturno, os animais foram submetidos aos testes.

Os animais foram submetidos à eutanásia com sobredose de Isoflurano seguido de exsanguinação por punção cardíaca. Todos os métodos foram realizados de acordo com o 
Conselho Nacional de Controle de Experimentação Animal (CONCEA). O projeto foi submetido à avaliação e aprovação da Comissão de Ética do Uso de Animais (CEUA) da Universidade Federal da Grande Dourados (UFGD), sob protocolo $n^{\circ}$ 22/2015.

\section{Labirinto em Cruz Elevado}

Para avaliação do efeito ansiolítico do OPAP, aplicou-se o teste Labirinto em Cruz Elevado. O comportamento foi avaliado quando o animal foi alocado no centro do aparato, durante 300 segundos, em ambiente escuro e sob incidência de luz vermelha. Os parâmetros avaliados foram: latência (s), elevação das patas frontais $\left(n^{\circ}\right)$, autolimpeza $\left(n^{\circ}\right)$, bolos fecais $\left(n^{\circ}\right)$, entradas no braço fechado $\left(n^{\circ}\right)$, tempo no braço fechado (s), entradas no braço aberto $\left(\mathrm{n}^{\circ}\right)$ e tempo no braço aberto (s).

\section{Campo Aberto}

Para avaliação do efeito ansiolítico do OPAP, aplicouse o teste Campo Aberto. Os animais foram alocados no centro do aparato e avaliados individualmente durante 300 segundos, sob incidência de luz vermelha. Os parâmetros avaliados foram: latência (s), tempo no centro (s), tempo nas laterais (s) e quadrados atravessados $\left(\mathrm{n}^{\circ}\right)$.

Esconder Esferas

Para avaliação do efeito ansiolítico do OPAP, aplicou-se o teste Esconder Esferas. Os animais foram alocados em caixa com maravalha a uma altura de 5 centímetros contendo 25 esferas brilhosas na superfície. Os mesmos foram deixados em contato com as esferas por 1800 segundos em ambiente claro e incidência direta de luz. O parâmetro avaliado foi o número de esferas escondidas.

Nado Forçado

Para avaliação do efeito antidepressivo do OPAP, aplicou-se o teste Nado Forçado. Os animais foram alocados em um recipiente com água morna $\left(25^{\circ} \mathrm{C}\right)$ durante 900 segundos em ambiente claro. Anteriormente ao experimento, os animais foram submetidos ao treino. Os parâmetros avaliados foram: tempo de mobilidade (s), autolimpeza $\left(\mathrm{n}^{\circ}\right)$ e bolos fecais $\left(\mathrm{n}^{\circ}\right)$.

Análise Estatística

Os valores encontrados nos testes foram expressos em médias desvio padrão. A análise estatística foi submetida a ANOVA e, em seguida, de teste Dunnett $(\mathrm{p}<0,05)$.

\section{Resultados e discussão}

Estudos previamente realizados por nosso grupo de pesquisa demonstram que o óleo dos frutos de A. phalerata apresenta majoritariamente os carotenoides: -caroteno $(11,02 \mathrm{~g} / \mathrm{g} 0,30)$, -caroteno $(62,33 \mathrm{~g} / \mathrm{g} \mathrm{0,70)}$ e -caroteno $(1,94$ $\mathrm{g} / \mathrm{g} 0,70)$, que demonstraram atividade anti-inflamatória em células de camundongos e em modelos in vivo com ratos Wistar(14,17); os ácidos graxos: ácido oleico 57,180,11), ácido linoleico $(20,080,02)$ e ácido palmítico $(14,53 \% 0,09)$, que possivelmente desempenharam diminuição dos níveis de colesterol, triglicerídeos e glicose em modelos in vivo com ratas/ratos Wistar(15).

Dentre os estudos desenvolvidos com o OPAP foram encontrados aminoácidos essenciais, sendo eles: isoleucina, metionina, treonina, triptofano e valina, que de acordo com estudos podem desenvolver atividade benéfica no sistema nervoso(17). Diante da composição química do óleo, resolveu-se testar os possíveis efeitos do OPAP no sistema nervoso.

Os distúrbios da ansiedade como a ansiedade generalizada, pânico ou fobias são os tipos mais comuns de doenças mentais. Por esse motivo, a descoberta de novos psicofármacos se tornou uma área de interesse na pesquisa pré-clínica e clínica $(18,19)$. Atualmente, existe um grande número de plantas medicinais cujo potencial terapêutico para esses distúrbios tem sido avaliado em modelos animais, e cujo mecanismo de ação tem sido investigado por ensaios neuroquímicos(7). Os testes mais utilizados para estudar os efeitos centrais de substâncias são o labirinto em cruz elevado (LCE), o campo aberto (CA), o esconder esferas (EE) e o nado forçado (NF). Tais modelos têm provido informações úteis para o desenvolvimento de novas farmacoterapias a partir de produtos naturais para o tratamento dos distúrbios da ansiedade e depressão(20-24).

Nesse estudo, ao observar o comportamento dos animais alocados no LCE (Figura 1), tempo de latência e frequência de autolimpeza, não houveram alterações estatísticas significativas quando comparados aos animais do grupo controle negativo. Já os animais tratados com $125 \mathrm{mg} / \mathrm{kg}$ e $500 \mathrm{mg} / \mathrm{kg}$ do OPAP apresentaram diminuição no número de vezes que ficaram sobre as duas patas traseiras (rearing), sendo que o baixo nível de rearing está correlacionado com o nível de ansiedade do animal. Por outro lado, todos os grupos tratados apresentaram diminuição no número de bolos fecais, sendo essa diminuição atribuída a um efeito ansiolítico. Durante a realização do teste, a frequência de autolimpeza, o número de bolos fecais e rearing são indicativos do estado emocional do animal(7).

Ainda no mesmo experimento, os ratos tratados oralmente com o OPAP, não alteraram a atividade locomotora ou a coordenação motora. Contudo, houve aumento no número de entradas e tempo gasto nos braços abertos no teste de LCE (Figura 2) nas doses de $125 \mathrm{mg} / \mathrm{kg}$ e $250 \mathrm{mg} / \mathrm{kg}$. Esse comportamento de explorar os braços abertos pode indicar efeito ansiolítico nas duas doses avaliadas, uma vez que o comportamento exploratório maior indica menor grau de ansiedade $(25,26)$.

Durante o experimento de CA, os ratos tratados oralmente com OPAP demonstraram menor tempo de latência nas doses de $250 \mathrm{mg} / \mathrm{kg}, 500 \mathrm{mg} / \mathrm{kg}$ e $1000 \mathrm{mg} / \mathrm{kg}$ (Figura 3 ). Porém, nos parâmetros tempo de permanência no centro, tempo na periferia e número de quadrados atravessados não apresentaram diferença estatística em relação ao grupo controle negativo.

Este teste permite a quantificação da atividade locomotora do animal. Os resultados do teste não comprovaram 

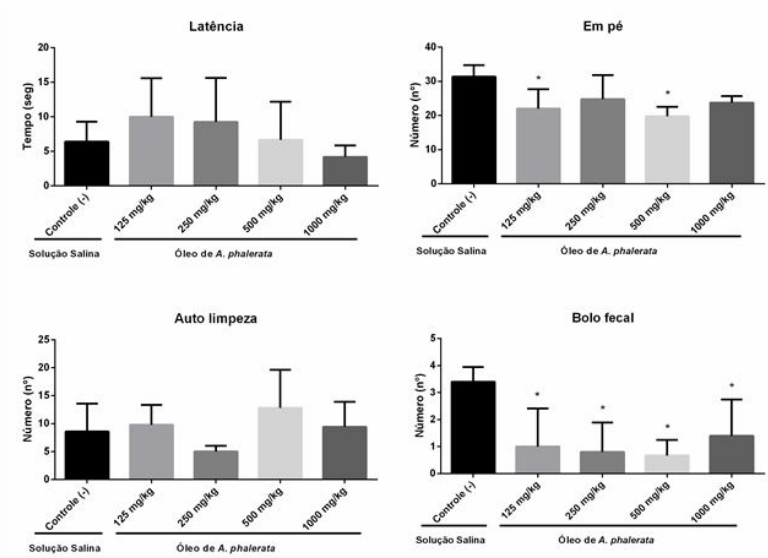

Os resultados são expressos em média \pm desvio padrão. Os valores foram submetidos a análise de variância (ANOVA) seguido de teste Dunnett $(p<0.05)$. Grupos identificados com asterisco $\left({ }^{*}\right)$ demonstram diferença estatistica do controle.

Figura 1. Efeito ansiolítico em ratos tratados com óleo da polpa dos frutos de A. phalerata via oral expostos ao teste de Labirinto em Cruz Elevado.
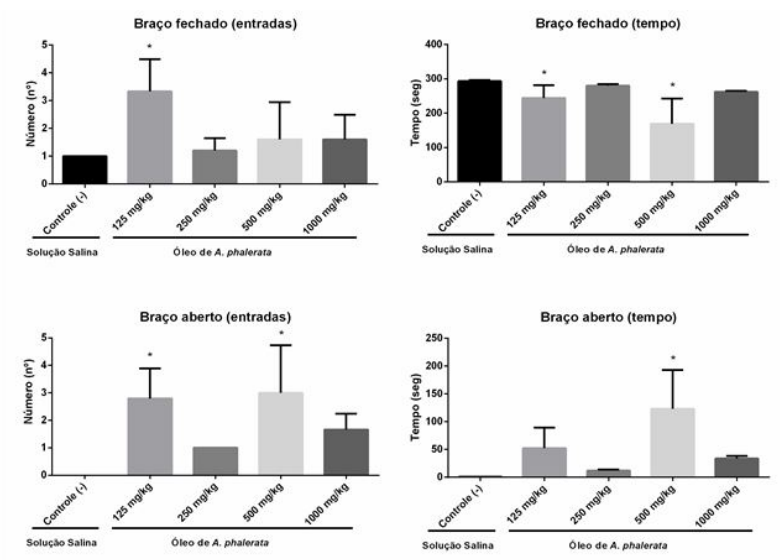

Os resultados são expressos em média \pm desvio padrão. Os valores foram submetidos a análise de variância (ANOVA) seguido de teste Dunnett $(p<0.05)$. Grupos identificados com asterisco $(*)$ demonstram diferença estatística do controle.

Figura 2. Efeito ansiolítico em ratos tratados com óleo da polpa dos frutos de A. phalerata via oral expostos ao teste de Labirinto em Cruz Elevado.

efeito ansiolítico apesar da diminuição do tempo de latência, também foi possível notar que o OPAP não apresenta influência na atividade locomotora dos animais.

A análise comportamental pelo experimento do teste $\mathrm{EE}$ mostrou que as doses de $125 \mathrm{mg} / \mathrm{kg}, 250 \mathrm{mg} / \mathrm{kg}$ e $500 \mathrm{mg} / \mathrm{kg}$ do OPAP levaram a diminuição no número de esferas escondidas, indicando possível efeito ansiolítico (Figura 4). $\mathrm{O}$ teste de EE possui como princípio o comportamento dos animais em esconder objetos que representam ou estão associados a estímulos aversivos, sendo considerado um comportamento de defesa(22). Este comportamento é

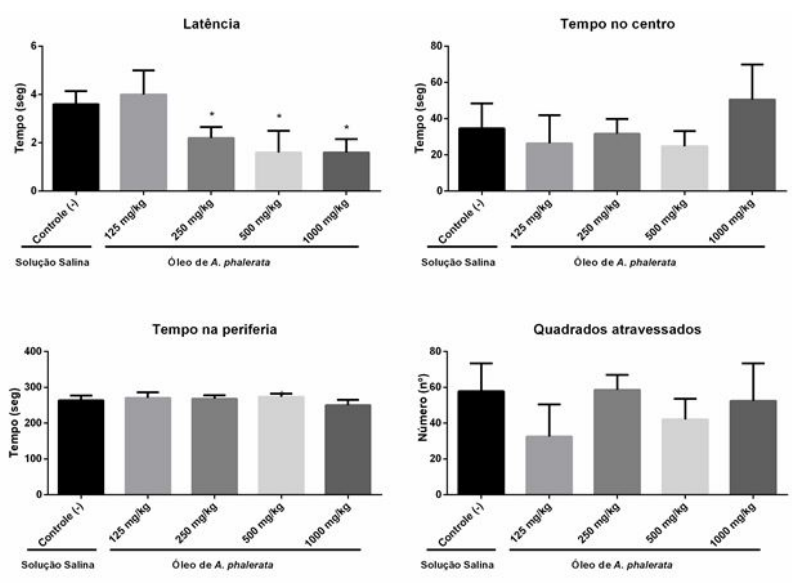

Os resultados são expressos em média \pm desvio padrão. Os valores foram submetidos a análise de variância (ANOVA) seguido de teste Dunnett $(p<0.05)$. Grupos identificados com asterisco $(*)$ demonstram diferença estatística do controle.

Figura 3. Efeito ansiolítico em ratos tratados com óleo da polpa dos frutos de A. phalerata via oral expostos ao teste de Campo Aberto

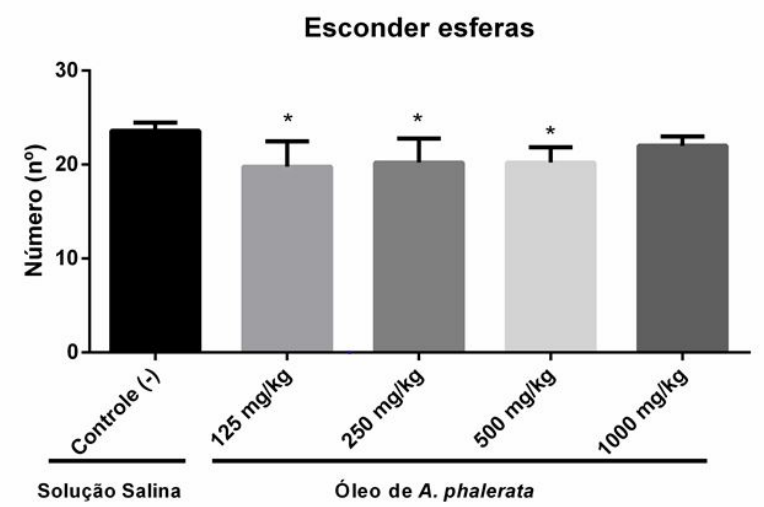

Os resultados são expressos em média \pm desvio padrão. Os valores foram submetidos a análise de variância (ANOVA) seguido de teste Dunnett $(p<0.05)$. Grupos identificados com asterisco $(*)$ demonstram diferença estatística do controle.

Figura 4. Efeito ansiolítico em ratos tratados com óleo da polpa dos frutos de $A$. phalerata via oral expostos ao teste de Esconder Esferas.

observado em ratos quando enterram alguma fonte de choque, alimentos nocivos ou objetos inanimados, como as esferas de vidro aplicadas neste estudo. O teste demonstra certa correlação ao transtorno obsessivo compulsivo, um tipo específico de ansiedade, que é tratado com os inibidores seletivos da serotonina(27).

O teste do NF é um modelo experimental para avaliar a atividade antidepressiva e associa essa atividade à redução no tempo de imobilidade dos ratos submetidos ao teste. $\mathrm{O}$ teste apresenta correlação com drogas que atuam 


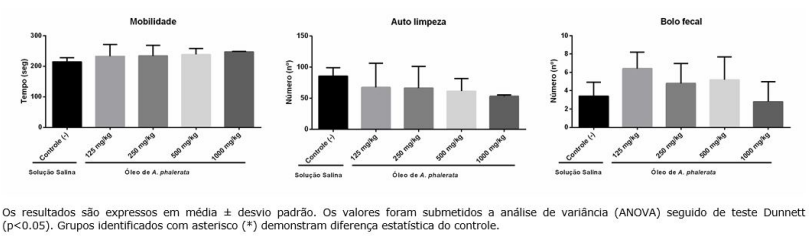

Figura 5. Efeito antidepressivo em ratos tratados com óleo da polpa dos frutos de A. phalerata via oral expostos ao teste de Nado Forçado.

sobre os sistemas de neurotransmissão mediados por noradrenalina (NOR) e serotonina $(5-\mathrm{HT})(23)$. Durante o NF foram avaliados os parâmetros de mobilidade, autolimpeza e número de bolos fecais. Quando avaliado o efeito antidepressivo do OPAP administrado oralmente nos ratos, os animais não apresentaram alteração comportamental estatisticamente significativa em nenhum dos parâmetros avaliados (Figura 5).

\section{Conclusão}

Diante dos resultados, conclui-se que o óleo da polpa de Attalea phalerata Mart. ex Spreng, nos modelos experimentais utilizados, não apresentou efeito sedativo (LCE) e apresentou efeito ansiolítico (EE). Entretanto, nos experimentos de campo aberto e nado forçado, os animais não apresentaram alterações comportamentais significativas entre os grupos testados. Os estudos dessa natureza são importantes para o desenvolvimento de fitoterápicos e aumentar as possibilidades terapêuticas para o tratamento dos distúrbios de ansiedade e depressão. Porém, deve-se destacar que estudos neurocomportamentais, precisam ser conduzidos de maneira minuciosa, com conhecimento da ação do fitoterápico e elucidação dos mecanismos de ação.

\section{Referências}

1. Ferry S, Baltassat-Millet F. La prospection des plantes medicinales. Lyon Pharma. 1997;28:257-60.

2. Williamson EM, Okpako DT, Evans FJ. Selection, preparation and pharmacological evaluation of plant material. J. Med. Chem. 1996;40(10):1559-1559.

3. Albuquerque UP, Hanazaki N. As pesquisas etnodirigidas na descoberta de novos fármacos de interesse médico e farmacêutico: fragilidades e pespectivas. Rev. Bras. Farmacogn. 2006;16(Suppl 0):678-89.

4. Cryan JF, Valentino RJ, Lucki I. Assessing substrates underlying the behavioral effects of antidepressants using the modified rat forced swimming test. Neurosci. Biobehav. Rev. 2005;29(4-5):547-69.

5. Fajemiroye JO, da Silva DM, de Oliveira DR, Costa EA. Treatment of anxiety and depression: medicinal plants in retrospect. Fundam. Clin. Pharmacol. 2016;30(3):198-215.
6. Duke JA. Medicinal plants and the pharmaceutical industry. New Crops. 1993:664-9.

7. World Health Organization - WHO. WHO Traditional Medicine Strategy 2014-2023. Geneva. World Health Organization, 2014. [cited 2018 may 18]. Available from: Disponível em: <http://apps.who.int/iris/bitstream/ 10665/92455/1/9789241506090 ng.pdf?ua = $1>$ .Acessoem : 09/05/2018.

8. Hornik-Lurie T, Cwikel J, Feinson MC, Lerner Y, Zilber N. Use of unconventional therapies by primary care patients - Religious resources vs. complementary or alternative medicine services. Complement. Ther. Med. 2013;21(5):517-24.

9. Dias DA, Urban S, Roessner U. A Historical Overview of Natural Products in Drug Discovery. Metabolites. 2012;2(4):303-36.

10. ANVISA. Consolidado de normas da COFID. Versão V. Agência de Vigilância Sanitária, 2015.

11. European Medicines Agenvcy - EMA. Herbal medicines for human use. [cited 2018 may 03]. Available from: http://www.ema.europa.eu/ema/index. jsp?curl=pages \%2Fmedicines\%2Flanding \%2Fherbal_search. jspmid=WC0b01ac058001fa1d searchkwByEnter= falsealreadyLoaded $=$ trueisNewQuery $=$ truekeyword $=$ Enter+keywordssearchType $=$ Latin+name + of + the + genus taxonomyPath=treeNumber.

12. De Lima FF, Menegati SELT, Traesel, GK, Souza de Araujo FH, Lescano CH, Peixoto SM et al. Study on the Cytotoxic, Genotoxic and Clastogenic Potential of Attalea phalerata Mart. ex Spreng. Oil Pulp In Vitro and In Vivo Experimental Models. Plos One. 2016;11(10):e0165258.

13. Lima FF, Traesel GK, Menegati SELT, dos Santos AC, Souza RIC, de Oliveira VS et al. Acute and subacute oral toxicity assessment of the oil extracted from Attalea phalerata Mart ex Spreng. pulp fruit in rats. Food Res. Int. 2017;91:11-7.

14. Balslev H, Moraes, M. Sinopsis de las palmeras de Bolivia. Rep. Bot. Inst. Univ. Aarhus. 1989;(20):101-7.

15. Negrelle RRB. Attalea phalerata Mart. ex Spreng.: aspectos botânicos, ecológicos, etnobotânicos e agronômicos. Cien. Florestal. 2015;25(4):1061-66.

16. Lima FF. Microencapsulação do óleo de bacuri por coacervação complexa: Obtenção, caracterização e avaliação biológica [dissertation]. Dourados: Faculdade de Ciências Exatas e Tecnologias/UFGD; 2014. 64 p.

17. De Lima FF, Lescano $\mathrm{CH}$, da Silva Arrigo J, Cardoso CAL, Coutinho JP, Moslaves ISB et al. Antiinflammatory, antiproliferative and cytoprotective potential of the Attalea phalerata Mart. ex Spreng. pulp oil. Plos One. 2018;13(4):e0195678.

18. Butler MS. Natural products to drugs: natural product-derived compounds in clinical trials. Nat. Prod. Rep. 2008;25(3):475-516.

19. Dresen S, Ferreirós N, Pütz M, Westphal F, Zimmermann R, Auwärter V. Monitoring of herbal mixtures potentially containing synthetic cannabinoids as psychoactive compounds. J. Mass. Spectrom. 2010;45(10):1186-94.

20. Hall CS. Emotional behavior in the rat: I. Defecation and urination as measures of individual differences in emotionality. J. Comp. Psychol. 1934;18:385-403.

21. Handley SL, Mithani S. Effects of alphaadrenoreceptor agonist in a maze-exploration model of 
"fear-motivated behavior. Naunyn Schmiedebergs Arch. Pharmacol. 1984;327(1):1-5.

22. Pellow S, Chopin P, File SE, Briley M. Validation of open: closed arm entries in the elevated plus-maze as a measure of anxiety in the rat. J. Neurosci Methods. 1985;14(3):149-67.

23. Broekkamp CL, Rijk HW, Joly-Gelouin D, Lloyd KL. Major tranquillizers can be distinguished from minor tranquillizers on the basis of effects on marble burying and swim-induced grooming in mice. Eur. J. Pharmacol. 1986;126(3):223-29.

24. Cryan JF, Markou A, Lucki I. Assessing antidepressant activity in rodents: recent developments and future needs. Trends Pharmacol. Sci. 2002;23(5):238-245.
25. Jung JW, Lee S. Anxiolytic Effects of Quercetin: Involvement of GABAergic System. J. Life Sci. 2014;24(3):290-6.

26. Aslam M, Hussain, SZ. Anxiolytic-like Activity of Methanol Extract of Leaves of Cydonia oblonga Miller (Quince) in Mice. Ethnopharmacol. 2015;2015(3):96-101.

27. Ichimaru Y, Egawa T, Sawa A. 5-HT 1A- Receptor Subtype Mediates the Effect of Fluvoxamine, a Selective Serotonin Reuptake Inhibitor, on Marble-Burying Behavior in Mice. Jpn. J. Pharmacol.1995;68(1):65-70. 